\title{
Endogenous Opioid Activity Is Associated with Obsessive-Compulsive Symptomology in Individuals with a Family History of Alcoholism
}

\author{
Deborah L. Mangold, M.A., Mark Peyrot, Ph.D., Paul Giggey, B.A., and Gary S. Wand, M.D.
}

Endogenous opioid activity has been associated with the regulation of mood and inhibition of the hypothalamicpituitary-adrenal (HPA) axis. We assessed differences in psychological symptomology and naloxone sensitivity in non-alcoholic males and females with a family history of alcoholism (FHP) and without a family history of alcoholism (FHN). This was followed by assessment of the association between naloxone sensitivity and psychological symptomology. Psychological symptomology was measured using the Revised Symptom Checklist (SCL-90R) during enrollment. Adrenocorticotropin was measured following intravenous administration of naloxone/placebo. FHP males reported more obsessive-compulsive symptomology as well as increased sensitivity to naloxone relative to other groups. A positive association was observed between degree of obsessive-compulsive symptomology and naloxone sensitivity, and the association was strongest among FHP males. These findings suggest that the increased risk of alcoholism in FHP subjects (especially males) may be associated with altered opioid activity, which is expressed through an elevated level of obsessive compulsive symptomology.

[Neuropsychopharmacology 22:595-607, 2000] (C) 2000 American College of Neuropsychopharmacology. Published by Elsevier Science Inc.
KEY WORDS: Naloxone; Adrenocorticotropin; Opioids; Alcoholism; Hypothalamic-Pituitary-Adrenal Axis

Family history of alcohol dependence is a strong predictor of risk for the future development of alcoholism (Goodwin 1985; Cloninger 1981; McGue et al. 1992). Adult sons of alcoholic fathers have a three to four-fold higher risk for this disorder compared to the male offspring of non-alcoholic fathers (Schuckit 1981).

From the Johns Hopkins University School of Medicine, Baltimore, MD 21205.

Address correspondence to: Gary Wand, M.D. Professor of Medicine, The Johns Hopkins University School of Medicine Ross Research Building Room 850, 720 Rutland Avenue, Baltimore, MD 21205, Tel.: 410-955-7225, Fax: 410-955-0841, E-mail: GWAND@ WELCHLINK.WELCH.JHU.EDU
These findings have led investigators to examine the presence of a wide range of possible psychological as well as neurobiological mediators for the development of alcoholism in individuals with a positive family history (FHP) for alcoholism (Pihl et al. 1990; Martin and Sher 1994; Baker and Stephenson 1995). A wide range of psychological differences have been specifically associated with FHP males relative to controls, including impulsivity (Saunders and Schuckit 1981; Schulsinger et al. 1985), conduct disorder (Nylander and Rydelius 1982), antisocial personality with or without hyperactivity (Alterman et al. 1983), attention deficit disorder (Gillen and Hesselbrock 1992; Deckel et al. 1995), and aggressiveness (Windle 1990). Along with psychological differences, alterations in neuroendocrine function following acute ethanol ingestion have been demonstrated in alcoholic males and males with a positive 
family history for alcoholism compared with normals (Newlin and Thomson 1990; Schuckit et al. 1988,1996; Waltman et al. 1994).

A growing body of literature suggests that the endogenous opioid system modulates a wide range of psychological symptomology, as well as the functioning of the Hypothalamic-Pituitary-Adrenal (HPA) axis (Pickar et al. 1982; Olson et al. 1996). It has been speculated that the interplay between environmental and genetic determinants generates a spectrum of endogenous opioid activity in the human population which, in the extreme ranges of opioid expression, lead to disturbances in mood, behavior and neuroendocrine function (Wand et al. 1998; Wand 1999; Blevins et al. 1994). Major behavioral alterations have been induced by opioid blockade with naloxone, suggesting the involvement of the endogenous opioid system in the tonic regulation of mood, behavior and cognition in normal (Cohen et al. 1983; Martin del Campo et al. 1992, 1994) and psychiatric populations (Insel and Pickar 1983; Sandyk 1987; Pickar et al. 1982). Some clinical studies suggest that in addition to the serotonergic system, the opioidergic system may be implicated in obsessive-compulsive symptomology (Carrion 1995; Insel and Pickar 1983; Keuler et al. 1996; Rapoport et al. 1992). Plasma B-endorphin levels have been found to be significantly lower in OCD subjects than in controls (Weizman et al. 1990). Studies with OCD subjects have shown naloxone decreases obsessional doubt and compulsive behaviors at low doses (Insel and Pickar 1983; Keuler et al. 1996) and decreases at higher doses (Sandyk 1987) in a small subgroup of subjects. Furthermore, opioid agents have been reported to affect stereotypic behavior observed in animals and humans, suggesting possible contributions by these neurotransmitter systems in obsessive-compulsive symptomology (Rapoport 1990, Rapoport et al. 1992; Stein et al. 1994; Gietzen 1990; Dodman et al. 1988).

Based on the clinical similarities between the obsessive thoughts and compulsive behaviors of alcoholdependent subjects and those of patients with obsessive-compulsive symptomology, and evidence that serotonin reuptake inhibitors used in the treatment of OCD are also effective in inhibiting volitional drinking (Naranjo et al. 1987) alcohol dependence has been compared to OCD (Modell et al. 1992a, 1992b). Although the experience of compulsive "alcohol seeking" and "craving" reported by alcoholics long after withdrawal can not be equated with obsessive-compulsive symptomology, there may be some behavioral similarities. Observations of behaviors associated with alcohol and drug withdrawal in animal studies along with clinical reports of patients in drug treatment suggest behavioral similarities between "drug seeking" behaviors and stereotypic behaviors reversed by opioid antagonists (Carrion 1995; Noel and Gratton 1995). Indeed, theories of alcohol dependence have suggested behavioral similarities (Anton 1996; Kranzler and Anton 1994) based on the clinical observation that alcohol "craving" involves "obsessive thoughts about alcohol use", followed by "compulsive drinking" (Modell et al. 1992a, 1992b). The relationship between obsessive-compulsive symptomology and "craving" has been strengthened by a study of alcoholics in treatment reporting decreased subjective symptom ratings on The Obsessive Compulsive Drinking Scale (OCDS) during alcohol reduction and increased ratings during relapse drinking (Anton et al. 1995). Higher scores on the OCDS have also been associated with increased severity of alcohol dependence and history of previous alcohol treatment (Moak et al. 1998). PET evidence suggests that severity of craving is associated with $m u$ opioid receptor binding observed during early cocaine withdrawal (Zubieta et al. 1996). SPECT evidence suggests naltrexone decreased regional cerebral blood flow in the basal ganglia and the left mesial temporal regions in a small sample of recently abstinent alcoholics compared with controls (Catafau et al. 1998). Interestingly, PET and SPECT evidence of basal ganglia metabolic and perfusion abnormalities have been found in OCD patients (Rapoport 1990).

Alterations in the opioid system were implicated in the development of alcoholism as early as 1976, when Goldstein (1976) suggested that a deficiency or abnormality in endogenous opioid activity might contribute to the development of addictive behavior. Since then, several closely related hypotheses have been formulated linking alterations in endogenous opioid activity with enhanced risk for the development of alcoholism (Froelich and Wand 1997; Reid et al. 1991; Herz 1997). In line with these hypotheses, Gianoulakis and colleagues (1996) found that a moderate dose of ethanol induces a significant increase in plasma $\beta$-endorphin related peptides in FHP subjects compared with subjects without a family history of alcoholism (FHN).

We hypothesize that differences in specific behavioral and neuroendocrine responses that distinguish FHP subjects from comparison groups result from altered endogenous opioid activity. To determine the validity of an opioid model for alcoholism, it is necessary to generate accurate measurements of endogenous opioid tone in human subjects. Historically, this has proven to be a potent strategy for directly testing the validity of opioid models in normal and psychiatric populations (Naber 1993; Cohen et al. 1983; Martin del Campo et al. 1992, 1994).

The present study is an extension of our earlier work employing opioid blockade to examine opioid activity in individuals at risk for the development of alcoholism (Wand et al. 1998; Wand et al. 1999). Based on the opioid deficiency hypothesis (Reid et al. 1991), we previously predicted and demonstrated that FHP subjects 
show increased sensitivity to naloxone compared with FHN subjects. The present study sought to extend our previous findings by: 1) examining the effects of family history and gender on adrenocorticotropin response to opioid blockade with naloxone; 2 ) examining the effects of family history and gender on baseline psychological symptomology and; 3 ) determining if there is an association between naloxone sensitivity and obsessive-compulsive symptomology.

\section{METHODS}

\section{Subjects}

A total of 250 respondents, between the ages of 18-25, were recruited by flyers posted at local schools and universities and ads placed in community newspapers published in Baltimore and surrounding areas for a study examining cortisol response to two doses of naloxone (Wand et al. 1998). After providing informed consent, respondents underwent a comprehensive screening interview to determine eligibility for enrollment in the study. All diagnoses were formulated on the basis of diagnostic criteria (American Psychiatric Association 1994) from the Diagnostic and Statistical Manual of Mental Disorders (DSM-IV) using assessment information obtained from screening interviews conducted by masters degreed psychologists, trained in the use of the Semi-Structured Assessment for the Genetics of Alcoholism (Buccholz et al. 1994). Respondents were assessed for past and current diagnoses of alcohol and substance dependence or abuse as well as Axis 1 psychiatric diagnoses (e.g., mood and anxiety disorders including obsessive-compulsive disorder) and Axis 2 diagnoses specified by the SSAGA I/II (e.g., antisocial personality disorder). Respondents determined to have a diagnosis of alcohol or drug abuse or dependence (including nicotine) or a DSM-IV, Axis 1 psychiatric diagnosis, were excluded from the study. Respondents determined to be free of past or present alcohol, substance or psychiatric diagnoses were administered the Family History Assessment Module (FHAM) to determine the presence or absence of a maternal and paternal familial history of alcoholism (Kosten et al. 1992). Phone interviews were then conducted with family members to validate FHAM reports of familial density of alcoholism. Phone interviews were then conducted with family members to validate subjects' FHAM reports of a positive or negative familial history of alcoholism. Subjects were excluded from enrollment in the study when it was not possible to obtain confirmation of FHAM reports from family members. Furthermore, subjects whose biological mothers met criteria for a history of alcohol dependence/abuse were excluded from the study. Medical history, physical examination and laboratory tests were completed to insure good health sta- tus prior to enrollment. Candidates who reported treatment with antidepressants, neuroleptics, mood stabilizers, sedative hypnotic medications, isoniazid, glucocorticoids, and appetite suppressants within the past 10 years were excluded from the study. A subject designated as family history negative had no history of alcohol abuse or dependence in any paternal first or second degree relative or any first-degree maternal relative. A family history positive subject was one whose biological father and at least one additional relative met diagnostic criteria for alcohol dependence. This study includes forty-eight of the original 60 subjects reported in Wand et al. (1999). In the original study, we examined ACTH responses to only one dose of naloxone and did not report behavioral findings. We now report on 48 of the original subjects who initially consented to three randomized, double blind sessions (e.g., placebo and two doses of naloxone) and behavioral assessments.

Psychometric Instrumentation. The Revised Symptom Checklist (SCL-90-R) is a self-report, clinical rating scale providing global indices and scores on symptom dimensions regarding mental health, overall well being and psychological distress (Derogatis 1977). The instrument is comprised of 90 items across nine symptom categories: Somatization, Obsessive-Compulsive (O-C), Interpersonal Sensitivity, Depression, Anxiety, Hostility, Phobic, Paranoid Ideation, and Psychoticism. Subject responses to each of these items provide information on the intensity ( 5 -point scale: not at all; a little bit; moderately; quite a bit; extremely) in the past seven days before completing the questionnaire. Each of the scales has exhibited a good internal consistency coefficient (coefficient alpha from 0.77 to 0.90 ) and a high concurrent validity with MMPI clinical profiles (Derogatis et al. 1976). Factor analysis studies have confirmed the existence of independent factors corresponding to the dimensions of the scale (Derogatis and Cleary 1977a, 1977b). The SCL-90-R was administered to subjects during the initial assessment interview.

Neuroendocrine Protocol. Subjects reported for sessions at $1230 \mathrm{~h}$ fasting since $0900 \mathrm{~h}$ breakfast. At each session, an intravenous catheter was inserted into a forearm vein at $1300 \mathrm{~h}$. One hour following intravenous line placement, naloxone hydrochloride dissolved in $0.9 \%$ isotonic sodium chloride or placebo $(0.9 \%$ isotonic sodium chloride) was administered foronemin as a bolus dose. Baseline blood samples were obtained $15 \mathrm{~min}$ before, and immediately before drug administration. Blood samples were drawn at 15, 30, 45, 60, 90 and 120 min after drug or placebo administration. Naloxone hydrochloride $(0,125$, or $375 \mu \mathrm{g} / \mathrm{kg})$ and placebo were administered in a double blind, randomized dose order. The dose range for naloxone hydrochloride was selected to include a submaximal dose $(125 \mu \mathrm{g} / \mathrm{kg})$ based on the ability of naloxone to stimulate adrenocorticotro- 
pin secretion in healthy subjects (Wand et al. 1999). Each of the three doses was administered on a different day, separated by at least 72 hours. Female subjects completed all sessions during their follicular phase determined by menstrual history questionnaire and diary.

Neuroendocrine Assays. Plasma concentrations of adrenocorticotropin were measured by 2-site immunoradiometric assay (Nichols Institute, San Juan Capistrano, CA). Intra- and inter-assay coefficients of variance were less than $9 \%$ and $10 \%$, respectively. Naloxone concentrations were determined in plasma following the low dose administration of the drug by high performance liquid chromatography with dual electrode electrochemical detection, (National Medical Services, Willow Grove, PA). Intra- and interassay coefficients of variation were $3 \%$ and $6 \%$, respectively.

\section{Statistical Analyses}

The effects of four independent variables on measures of psychological symptomology (SCL90-R global and subscale scores) and neuroendocrine responses (adrenocorticotropin) were studied. The independent variables were time (a 2-hour session comprised of eight time points); naloxone dose (0, 125 or $375 \mu \mathrm{g} / \mathrm{kg})$; and subject characteristics including family history of alcoholism status and gender. All data were examined to determine compliance with the assumptions of each test (e.g., normality). Data tended to be non-normal and a square root transformation was performed. Significance was evaluated at .05 or less. All analyses were conducted with the Statistical Package for the Social Sciences (SPSS 1996).

Demographic Data. The relationship between gender and family history status was analyzed using a Chi Squared analysis. A One-way Analysis of Variance (ANOVA) was used to examine differences between groups on mean number of ethanol drinking episodes per week, number of ethanol drinks per episode, body mass index and plasma naloxone concentration.

Psychometric Data. Analyses were chosen to test two hypotheses: 1) FHP subjects report significantly more psychological distress across subscales relative to FHN subjects and; 2) FHP males report more distress relative to all comparison groups. The separate and combined effects of family history and gender on the individual subscales of the SCL-90-R at baseline were examined using an ANOVA. Significant multivariate results were analyzed by univariate tests for individual subscales and finally, contrasts were performed to test $a$ priori hypotheses comparing the symptomology reported by FHP males with the other groups.

Neuroendocrine Data. Two hypotheses were tested: 1) FHP subjects demonstrate an enhanced adrenocorti- cotropin response across time points following each dose of naloxone compared with FHN subjects and;2) FHP males demonstrate a significantly increased adrenocorticotropin response compared with other groups following placebo and $125 \mu \mathrm{g}$ of naloxone. Repeated measures ANOVA with time as the repeated measure and dose, family history and gender as grouping factors, was performed to test for the separate and combined effects of family history status and gender on the adrenocorticotropin time curves, generated in response to each dose of naloxone. Specified contrast tests were used to determine whether at individual time points following placebo and $125 \mu \mathrm{g}$ of naloxone: 1) FHP males demonstrate increased adrenocorticotropin response compared with FHP females and; 2) FHP males demonstrate an increased adrenocorticotropin response compared with all comparison groups.

To confirm results obtained from time point data we calculated: 1) area under the adreno- corticotropin time curve (AUC), calculated over the 2-hour time interval using the trapezoidal rule (Altman 1991) and; 2) Delta (defined as the difference between peak neuroendocrine response and baseline).

Naloxone Sensitivity. Naloxone sensitivity was defined in terms of the ratio of delta values. Delta values were defined as the difference between the peak value and the zero time adreno- corticotropin value (prenaloxone administration). Naloxone sensitivity was expressed as the ratio of the delta adrenocorticotropin value at the low dose of naloxone to the delta adrenocorticotropin response at the high dose. Defined in this way, increasing ratio values indicate increasing sensitivity to naloxone in regards to its ability to induce a maximal adreno- corticotropin response. Therefore, individuals whose adrenocorticotropin responses result in larger ratio delta values demonstrate an enhanced sensitivity to naloxone. Multiple regression was used to test the degree to which neuroendocrine responsiveness to opioid receptor blockade (e.g., sensitivity to naloxone) is associated with baseline symptomology for the entire subject sample as well as FHP subjects.

\section{Results}

Demographic Data. Subject demographic characteristics are presented in Table 1 . Subjects averaged 21 years of age, completed at least one year of college and were predominantly white. Typically, subjects drank alcohol one day per week, averaging three drinks per episode. The four subject groups did not differ on plasma naloxone concentration levels, age, sex, racial representation, body mass index or alcohol drinking histories. All family history positive subjects had fathers meeting diagnostic criteria for alcohol-dependence; $81 \%$ of family history positive subjects had second degree paternal 
Table 1. Subject Demographics

\begin{tabular}{|c|c|c|c|c|}
\hline & \multicolumn{2}{|c|}{$\begin{array}{l}\text { Family History } \\
\text { Positive Subjects }\end{array}$} & \multicolumn{2}{|c|}{$\begin{array}{l}\text { Family History } \\
\text { Negative Subjects }\end{array}$} \\
\hline Sample Size & 26 & & 22 & \\
\hline Female & 15 & & 10 & \\
\hline Male & 11 & & 12 & \\
\hline \multicolumn{5}{|l|}{ Race } \\
\hline Caucasian & 24 & & 19 & \\
\hline Afro-American & 1 & & 1 & \\
\hline Asian & 1 & & 2 & \\
\hline Age (years) & $21 \pm 0.5$ & & $21 \pm 0.4$ & \\
\hline \multicolumn{5}{|l|}{ Body Mass Index $\left(\mathrm{kg} / \mathrm{m}^{2}\right)$} \\
\hline Males & $24 \pm 1.0$ & & $27 \pm 1.0$ & \\
\hline Females & $22 \pm 1.0$ & & $24 \pm 1.0$ & \\
\hline \multicolumn{5}{|c|}{ Drinks per drinking episode } \\
\hline Males & $4.0 \pm 1.2$ & & $3.4 \pm 0.8$ & \\
\hline Females & $4.3 \pm 0.9$ & & $2.7 \pm 0.6$ & \\
\hline \multicolumn{5}{|l|}{ Drinking episodes per week } \\
\hline Males & $1.8 \pm 0.5$ & & $1.4 \pm 0.3$ & \\
\hline Females & $1.2 \pm 0.4$ & & $0.7 \pm 0.2$ & \\
\hline Family History Density* & $1^{\circ}$ & $2^{\circ}$ & $1^{\circ}$ & $2^{\circ}$ \\
\hline \multicolumn{5}{|l|}{ Males } \\
\hline Paternal & 100 & 72 & 0 & 0 \\
\hline Maternal & 0 & 11 & 0 & 8 \\
\hline \multicolumn{5}{|l|}{ Females } \\
\hline Paternal & 100 & 88 & 0 & 0 \\
\hline Maternal & 0 & 33 & 0 & 10 \\
\hline
\end{tabular}

relatives meeting diagnostic criteria for alcohol-dependence and $23 \%$ had second degree maternal relatives meeting diagnostic criteria for alcohol-dependence.

Psychometric Data. Results of the analyses of baseline psychometric data are presented in Table 2. Over- all, baseline SCL-90-R scores for the FHN subjects in our sample are in line with those reported by Derogatis (1977) for normal adult males and females. There was a significant interaction between family history and gender on psychological distress at baseline $(\mathrm{F}=1.835,16 / 62 \mathrm{df}$, $p=.046)$. Family history groups differed on five of nine

Table 2. Mean SCL90-R Scores at Baseline by Family History and Gender

\begin{tabular}{|c|c|c|c|c|c|c|c|c|}
\hline \multirow[b]{3}{*}{ Gender } & \multirow{2}{*}{\multicolumn{2}{|c|}{ Normals $^{a}$}} & \multicolumn{2}{|c|}{$\begin{array}{c}\text { Family History } \\
\text { Negative }\end{array}$} & \multicolumn{2}{|c|}{$\begin{array}{c}\text { Family History } \\
\text { Positive }\end{array}$} & \multirow[b]{3}{*}{ p Values } & \multirow{3}{*}{$\begin{array}{l}\text { Significant } \\
\text { Contrasts }\end{array}$} \\
\hline & & & 10 & 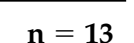 & 10 & & & \\
\hline & Males & Females & Males & Females & Males & Females & & \\
\hline \multicolumn{9}{|l|}{ Subscale } \\
\hline Anxiety & $.22(.27)$ & $.37(.43)$ & $.13(.19)$ & $.16(.18)$ & $.61(.29)$ & $.24(.20)$ & $F^{* *}$ & $1<3,2<3,4<3$ \\
\hline Depression & $.28(.31)$ & $.46(.52)$ & $.26(.26)$ & $.39(.25)$ & $.62(.42)$ & $.45(.32)$ & $\mathrm{F}^{*}, \mathrm{FxG} \mathrm{G}^{*}$ & $1<3,2<3,4<3$ \\
\hline Hostility & $.29(.37)$ & $.33(.42)$ & $.30(.22)$ & $.28(.27)$ & $.58(.52)$ & $.31(.23)$ & & \\
\hline Interpersonal Sensitivity & $.25(.31)$ & $.35(.43)$ & $.21(.19)$ & $.34(.34)$ & $.74(.44)$ & $.44(.35)$ & $\mathrm{F}^{* *}, \mathrm{FxG}^{*}$ & $1<3,2<3,4<3$ \\
\hline Obsessive-Compulsive & $.34(.39)$ & $.44(.49)$ & $.31(.25)$ & $.46(.32)$ & $.99(.52)$ & $.36(.34)$ & $F^{* *}, G^{*}, F x G^{* *}$ & $1<3,2<3,4<3$ \\
\hline Paranoid Ideation & $.34(.40)$ & $.34(.46)$ & $.06(.21)$ & $.26(.26)$ & $.69(.56)$ & $.36(.3)$ & $\mathrm{F}^{*}$ & \\
\hline Phobic Anxiety & $.08(.19)$ & $.19(.38)$ & $.00(.00)$ & $.09(.19)$ & $.17(.31)$ & $.06(.15)$ & & \\
\hline Psychoticism & $.13(.22)$ & $.15(.25)$ & $.02(.07)$ & $.12(.16)$ & $.32(.34)$ & $.15(.20)$ & $\mathrm{F}^{*}$ & \\
\hline Somatization & $.29(.33)$ & $.43(.47)$ & $.22(.23)$ & $.48(.19)$ & $.55(.31)$ & $.36(.20)$ & $\mathrm{FxG}^{* *}$ & $1<3,2<3,4<3$ \\
\hline Global Severity Index & $.25(.24)$ & $.36(.35)$ & $.25(.15)$ & $.35(.16)$ & $.67(.33)$ & $.36(.18)$ & $F^{* *}, F_{x G}^{* *}$ & $1<3,2<3,4<3$ \\
\hline
\end{tabular}

$\mathrm{F}=$ Family History is significant; $\mathrm{G}=$ Gender is significant; FxG = The interaction between Family History and Gender is significant.

Note: Standard Deviations are in parentheses.

${ }^{*} p<.05 ;{ }^{* *} p<.01$.

Contrasts listed are significant at $p<.05$.

Contrast Groups: FHN Males $=$ group $1 ;$ FHN Females $=$ group 2; FHP Males = group 3; FHP Females $=$ group 4.

${ }^{a}$ Copyright 1977, 1983, 1994, Leonard R. Derogatis, Ph.D., used by permission of NCS, Minneapolis, MN. 
subscales such that: FHP subjects were more likely to report symptomology associated with the psychological dimensions of Anxiety ( $\mathrm{F}=8.910,1 \mathrm{df}, p=.005)$, Depression $(\mathrm{F}=.4 .969, p=032)$, Interpersonal-Sensitivity $(\mathrm{F}=7.024,1 \mathrm{df} . p=.012)$, Obsessive-Compulsive $(\mathrm{F}=7.137,1 \mathrm{df}, p=.011)$, and Psychoticism $(\mathrm{F}=6.321$, $1 \mathrm{df}, \mathrm{P}=.016)$ than FHN subjects. FHP subjects reported more frequent symptoms of overall distress than FHN subjects, indicated by significantly higher scores on the GSI, ( $F=8.765,1 \mathrm{df}, \mathrm{P}=.005)$. A significant effect for gender was found only for the Obsessive-Compulsive subscale: males were more likely to report O-C than were females $(\mathrm{F}=5.165,1 \mathrm{df}, \mathrm{P}=.029)$. A significant interaction of family history and gender for psychological distress was found for three measures: Somatization $(\mathrm{F}=13.697,1 \mathrm{df}, \mathrm{P}=.001)$,Obsessive-Compulsive $(\mathrm{F}=11.868,1 \mathrm{df}, .001)$ and $\mathrm{GSI}(\mathrm{F}=8.106,1 \mathrm{df}, p=.007)$. FHP males were distinguished from other groups reporting more significantly more Anxiety $(t=3.273, P=.029)$, Depression $(\mathrm{t}=2.128, p=.05)$, Interpersonal Sensitivity $(\mathrm{t}=2.749, p=.02), \mathrm{O}-\mathrm{C}(\mathrm{t}=3.881, p=.002)$, Somatization $(\mathrm{t}=2.445, p=.030)$ and global distress $(\mathrm{t}=2.850, p=$ .017).

Neuroendocrine Data. Adrenocorticotropin time curves were generated for the entire sample. Different doses of naloxone induced differences in adrenocorticotropin responses across time points, indicated by a significant multivariate effect for time ( $\mathrm{F}=17.961,7 / 127 \mathrm{df}, p=$ $.000)$ and a significant interaction between time and dose $(\mathrm{F}=6.800,14 / 254 \mathrm{df}, p=.000)$.

Increasing doses of naloxone induced corresponding increases in adrenocorticotropin responses for the combined subject sample indicated by a significant univariate effect for dose $(\mathrm{F}=13.842,2 \mathrm{df}, p=.000)$. Adrenocorticotropin responses at the low dose were greater than placebo and adrenocorticotropin responses at the high dose were greater than at the low dose. Significant differences in adrenocorticotropin responses were observed between placebo and low dose at time points: $15(p=.007) ; 30(p=$ $.001) ; 45(p=.002) ; 60(p=.020)$, and between low dose and high dose at time points: 30 ( $p=.043) ; 45(p=.001)$; $60(p=.001) ; 90(p=.009) ; 120(p=.035)$.

Figure $1(\mathrm{~A}-\mathrm{F})$ presents adrenocorticotropin responses over time at each dose of naloxone by family history and gender. Different doses of naloxone induced differences in adrenocorticotropin responses across the time course $(\mathrm{F}=17.067,7 / 118 \mathrm{df}, p=.001)$. A significant between-subjects effect for the interaction of dose $\mathrm{X}$ family history $\mathrm{X}$ gender $(\mathrm{F}=3.232,11 \mathrm{df}, p=$ .001) showed FHP males have a greater adrenocorticotropin response to the placebo and low dose of naloxone relative to FHP women, whereas there was no difference in response between gender groups for FHN subjects to any dose of naloxone. In the FHP group, adrenocorticotropin response differed at placebo by gender at the following time points: $0(p=.021) ; 15(p=$ $.020) ; 30(p=.018) ; 60(p=.021) ; 90(p=.042)$; and after low dose at the following time points: $15(p=.013) ; 30$ $(p=.030) ; 45(p=.034) ; 60(p=.004) ; 90(p=.028) ; 120$ $(p=.021)$. Furthermore, FHP males demonstrated significantly increased adrenocorticotropin response in contrast to all other groups after placebo at the following time points: $0(p=.046) ; 15(p=.053) ; 30(p=.045)$; $60(p=.040)$; and after low dose at the following time points: $15(p=.015) ; 30(p=.039) ; 45(p=.042) ; 60(p=$ $.006) ; 90(p=.047)$.

Significant interactions of dose $X$ family history $X$ gender indicated differences between gender groups in adrenocorticotropin response following specific doses of naloxone for the FHP group but not the FHN group: AUC $(\mathrm{F}=2.259,9 \mathrm{df}, p=.025)$ and Delta $(\mathrm{F}=2.183,9$ $\mathrm{df}, p=.030$ ). FHP males demonstrated a significantly increased adrenocorticotropin response following low naloxone compared to FHP females and FHN subjects.

A comparison of within-group differences for each dose of naloxone demonstrates that FHN subjects as well as FHP women had a graded adrenocorticotropin response to each dose of naloxone. Among FHN subjects, significant increases in AUC and Delta were found following high dose relative to the low dose of naloxone within each gender group: FHN males; AUC $(p=.032)$; Delta $(p=.030)$; FHN females; $\operatorname{AUC}(p=$ $.016)$; Delta $(p=.002)$; FHP females; AUC $(p=.031)$; Delta ( $p=.027)$. In contrast, FHP males demonstrated a maximal adrenocorticotropin response to low dose naloxone, and no further increase in adreno- corticotropin was observed following high dose naloxone: AUC $(p=.789)$; Delta $(p=.675)$.

Naloxone Sensitivity. Naloxone sensitivity (see methods for definition of naloxone sensitivity) was able to successfully predict symptom scores for the entire subject sample on the Obsessive-Compulsive subscale $(r=$ $.34, p=.05)$, but not the Anxiety, Depression, Interpersonal-Sensitivity or Somatization subscales. As predicted, there was a significant correlation between naloxone sensitivity and obsessive-compulsive symptomology for FHP subjects $(\mathrm{r}=.45, p=.04)$ but not for FHN subjects.

\section{DISCUSSION}

The behavioral and neuroendocrine findings reported here provide evidence in support of altered endogenous hypothalamic opioid activity in high-risk (FHP) males. In our sample, increased sensitivity to opioid blockade and increased psychological symptomology distinguish high-risk males from the other groups. The enhanced adrenocorticotropin response to opioid blockade observed in high-risk males suggests diminished hypotha- 
A.

NEGATIVES

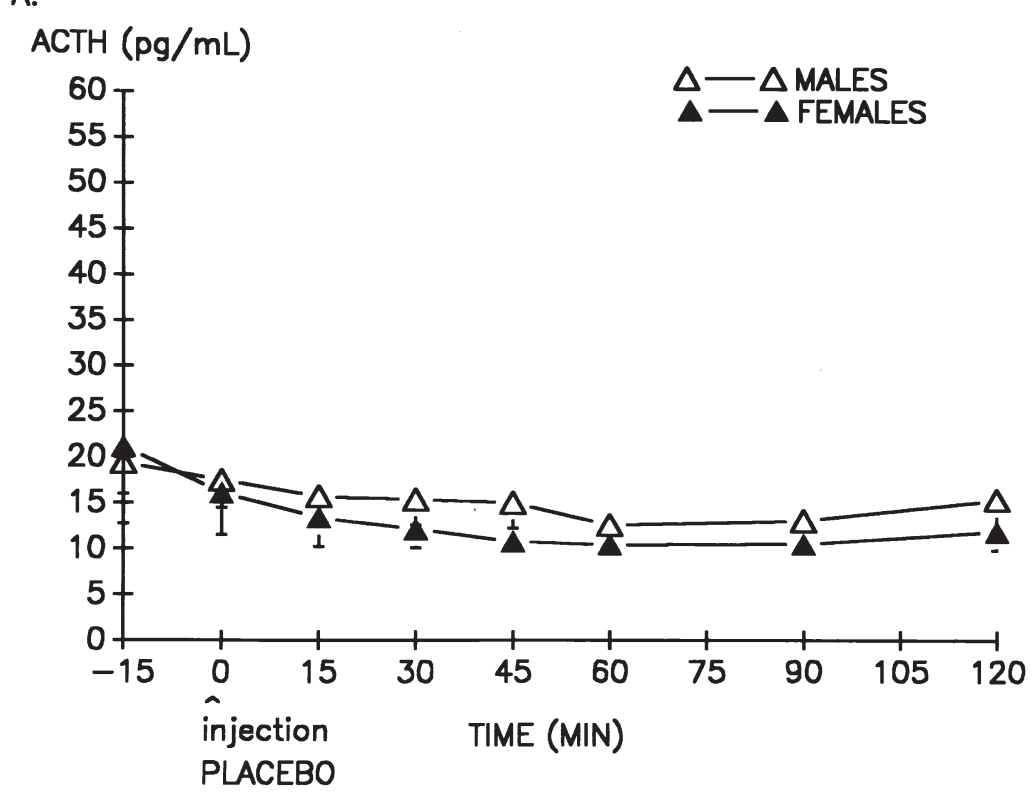

B.

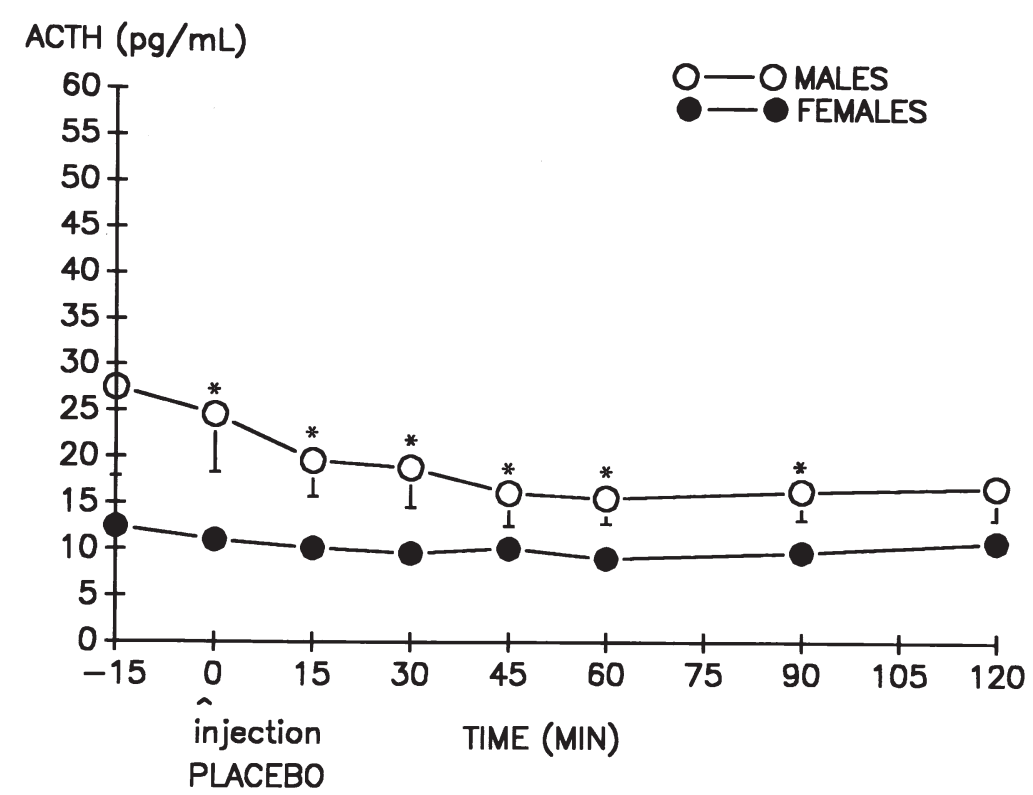

Figure 1. (A \& B) The effects of family history and gender on Adrenocorticotropin responses following administration of placebo. * indicates a significant difference between males and females subjects. FHP males demonstrated an enhanced adrenocorticotropin response compared to FHP females at time points $0(p=.021)$; $+15(p=.020) ;+30(p=.018) ;+45(p=.084) ;$ $+60(p=.021)$ and $+90(p=.042)$. No gender differences were found for FHN subjects following placebo administration. lamic opioid tone. Furthermore, diminished hypothalamic opioid tone is associated with increased reports of obsessive-compulsive symptomology in FHP individuals.

These findings replicate and extend our previous work (Wand and Dobs 1991; Wand et al. 1998, 1999) and the work of others (Schuckit et al. 1988, 1996; Lex et al. 1991; Gianoulakis et al. 1996) demonstrating significant differences in HPA axis dynamics as a function of family history of alcoholism. Our new findings suggest an interaction between family history and gender which significantly effects adrenocorticotropin response to opioid receptor blockade. This is demonstrated by an increased sensitivity to naloxone in FHP males compared to the other three groups (i.e., FHP males show a maximal adrenocorticotropin response to smaller doses of naloxone compared to FHP females and FHN subjects). This finding cannot be explained by differences in plasma naloxone concentration, since concentration following the low dose was similar for the four groups. Overall, these data provide further evidence suggesting alcohol-dependent men and their male offspring have alterations in brain opioid activity placing them at higher 
C.

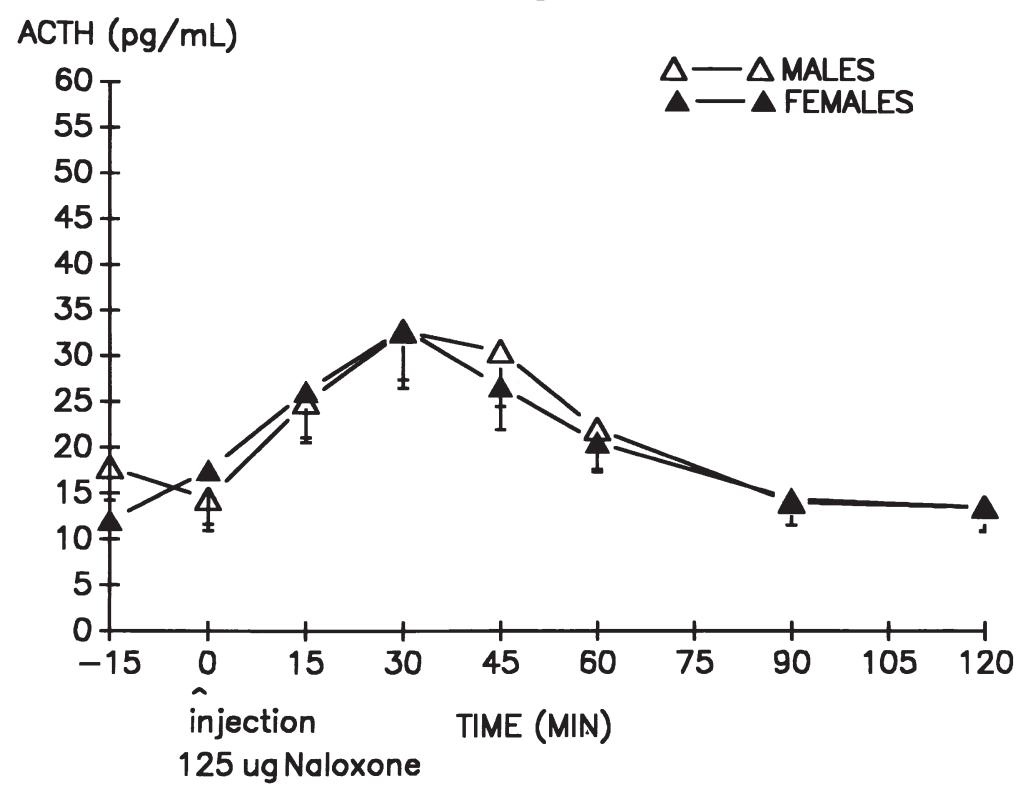

D.

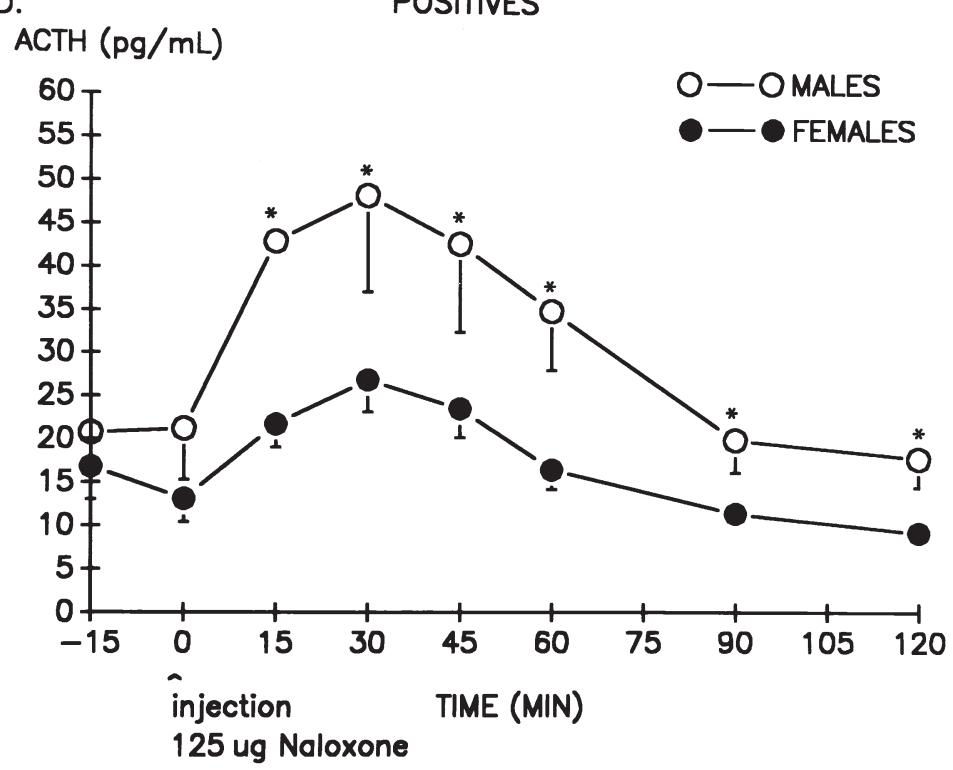

Figure 1. (C \& D) The effects of family history and gender on Adrenocorticotropin responses following administration of $125 \mu \mathrm{g} /$ $\mathrm{kg}$ of naloxone. Following administration of the lower dose of naloxone, a gender effect on Adrenocorticotropin responses was observed for FHP subjects. Males demonstrated enhanced adrenocorticotropin response compared to FHP females at time points $+15(p=.013)$; $+30(p=.030) ;+45(p=.034) ;+60(p=.004) ;$ $+90(p=.028)$ and $+120(p=.021)$. In contrast, no gender differences were found among FHN subjects following low dose naloxone administration. risk for the future development of alcoholism relative to individuals with a normal range of hypothalamic endogenous opioid activity. FHP women have a higher incidence of depression and lower incidence of alcoholism compared to FHP men suggesting that different pathophysiological mechanisms underlie alcoholism for men and women (Helzer and Pryzbeck 1988; Helzer et al. 1988; Hartka et al. 1991). One can speculate that the unique hormonal profile in FHP men compared to the other groups is somehow related to differences in the heritability of alcoholism for men and women.

Differences in naloxone sensitivity between FHP males and females may indicate that gender modulates the effect of family history status on endogenous hypothalamic opioid tone. Recent evidence indicates that estrogen regulates the synthesis of opioid peptides and their receptors in the hypothalamus in male and female rats (Hammer et al. 1994). Ovarectomy decreases and estrogen treatment increases the density of $m u$ opioid receptors in the preoptic areas of the mouse and rat (Romano et al. 1989). It has also been shown that proenkephalin gene contains cis regulatory elements regulated by estrogen (Priest et al. 1995) and estrogen treatment increases proenkephalin expression in the ventral medial nucleus of the hypothalamus of female and male rats (Romano et al. 1989; Priest et al. 1995). Increases in opioid binding have been reported in animals 
E.

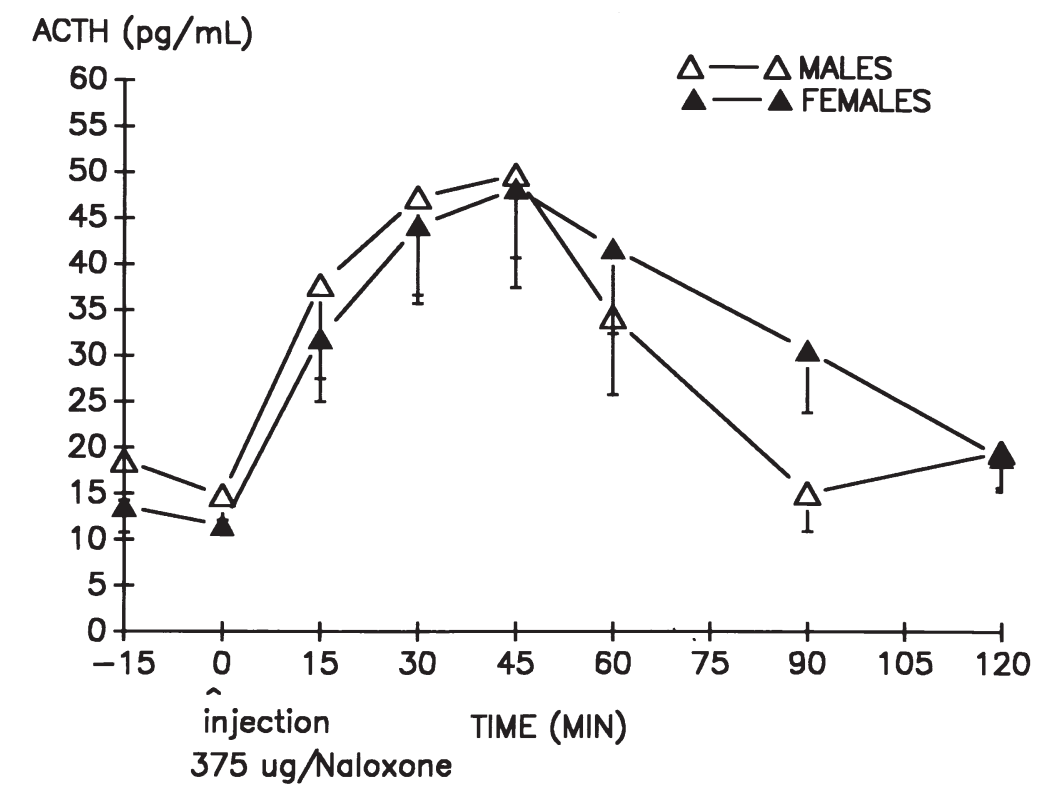

F.

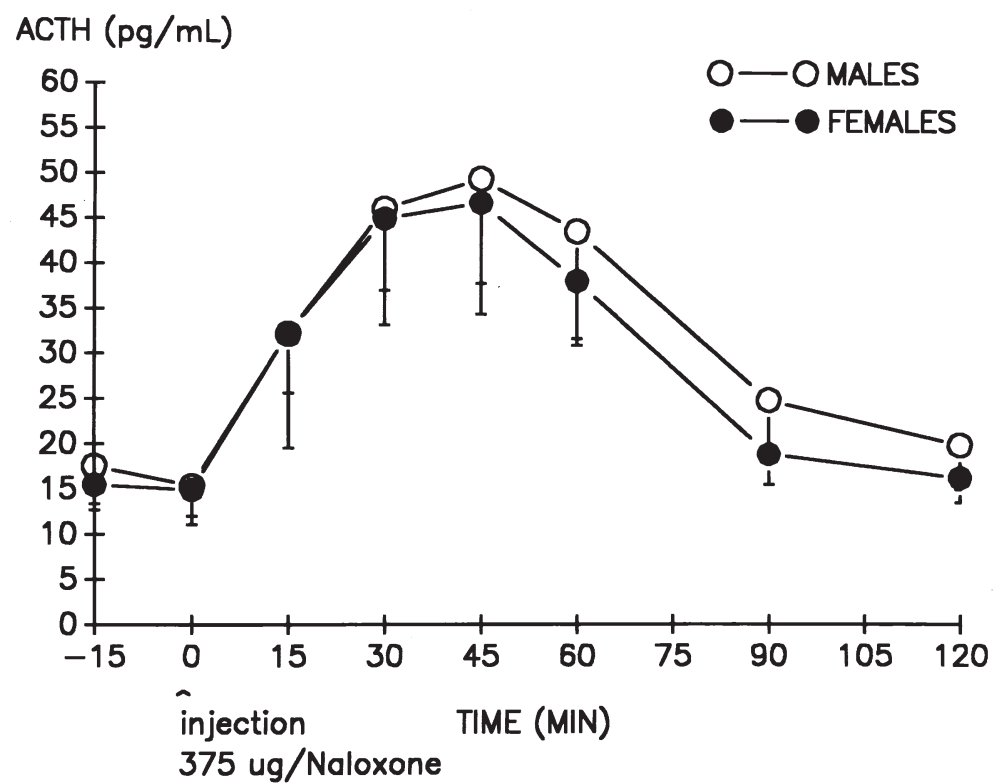

Figure 1. (E \& F) The effects of family history and gender on Adrenocorticotropin responses following administration of $375 \mu \mathrm{g} / \mathrm{kg}$ of naloxone. No gender differences in adrenocorticotropin response were observed for either family history group. chronically exposed to estrogen (Joshi et al. 1993). In mice, there is region specific loss of $m u$ opioid receptors following long-term ovarectomy (Joshi et al. 1993). Therefore, we speculate that estrogen may override the effects of family history on opioid activity and account for the apparently "normalized" ACTH response observed in FHP females.

Although subjects did not meet DSM IV diagnostic criteria for selected Axis I or 2 disorders, the psychological symptomology observed at baseline for FHP males and females in our sample more closely resembles norms for psychiatric outpatients than those of normal adults (Derogatis 1977). In our sample, relative to FHN individuals, offspring of alcohol dependent males re- port more symptomology associated with Anxiety, Depression, Interpersonal-Sensitivity, Obsession-Compulsion, Psychoticism and overall psychological distress. This finding is in line with previous research suggesting FHP individuals experience a higher level of subjective distress relative to normals (Sher et al. 1991). Furthermore, our finding that FHP males report more symptomology across several symptom dimensions compared with FHP females and FHN males and females is consistent with previous studies suggesting an interaction between gender and risk status for psychological symptomology (Kushner and Sher 1992; Bush et al. 1995).

Our findings support previous studies showing a 
positive association between opioid activity and obsessive-compulsive symptomology and supports the contention that, in addition to the serotonergic system, the opioidergic system may be implicated in obsessivecompulsive symptomology (Carrion 1995; Insel and Pickar 1983; Keuler et al. 1996; Rapoport et al. 1992). While the efficacy of selective serotonin reuptake inhibitors (SSRI) used in the treatment of OCD is well documented, only $40-60 \%$ of patients respond to treatment. The limitations of SSRI treatment suggest the possibility of other neurotransmitter and/or neuroendocrine system involvement in obsessive-compulsive symptomology (Goodman et al. 1989; Nurnberg et al. 1997).

A positive association was observed between Obsessive-Compulsive symptomology and endogenous opioid tone in FHP subjects. Altered opioid activity and increased Obsessive-compulsive symptomology can co-occur in FHP individuals, suggesting a common underlying neural substrate. Earlier studies have observed increased reports of obsessive-compulsive symptomology in alcoholic males during early (Mercier et al. 1992) and extended abstinence (DeSoto et al. 1985). These findings have prompted some researchers to speculate about the conceptual similarities between obsessive-compulsive symptomology and the experience of craving frequently reported by alcoholics during abstinence and prior to relapse (Modell et al. 1992b). These similarities have led some investigators to suggest craving can be conceptualized as a particular form of obsessional thinking and an important aspect of compulsive ethanol consumption (Anton 1996; Anton et al. 1995; Moak et al. 1998). The increased obsessive-compulsive symptomology in FHP males reported here is consistent with other findings of increased compulsivity in FHP males (Whipple and Noble 1991) and mirrors the presence of this symptomology in abstinent alcoholics (Mercier et al. 1992; Anton 1996; DeSoto et al. 1985). The presence of increased O-C symptomology in abstinent alcoholics as well as their male offspring indicates that it is not a sequelae of chronic alcohol use and may be present prior to the onset of alcohol abuse/dependence. In fact, a cortico-limbic-basal ganglia-thalamic circuit in obsessive-compulsive symptomology (Insel 1988; Baxter et al. 1991, 1992) involving the medial orbital gyri, the head of the caudate nucleus and nucleus accumbens has been proposed (Baxter et al. 1991), implicating the nucleus accumbens as a common opioidergic pathway involved in both ethanol reward and obsessive-compulsive symptomology.

Increased premorbid obsessive-compulsive symptomology may contribute to a heightened risk for the future development of alcoholism in FHP males as well as risk for relapse in abstinent alcoholics in several ways. The stress-dampening effects and expectancies for tension reduction of ethanol ingestion for some FHP individuals have been well-documented (Pohorecky 1991;
Kushner and Sher 1992; Sher and Levenson 1982). It is possible that the heightened overall psychological distress reported by FHP males or greater negative affectivity (Kushner and Sher 1992; Sher et al. 1991) in general, leads to an increased use of ethanol for its dampening effects. Indeed it has been suggested that stress may be followed by rebound deficiency of the endogenous opioid peptides, thus indirectly increasing the reinforcing actions of alcohol (Ulm et al. 1995).

An alternative explanation stems from documented clinical observations of the seemingly adaptive function served by episodic obsessive-compulsive symptoms (Franzblau et al. 1995), viewed by many patients as adaptive and integrated into their lives (Rasmussen and Tsuang 1984) and suggests that obsessive-compulsive behaviors may act to reduce perceived distress (Insel 1990; Steketee et al. 1987). It has been suggested that enhanced sensitivity to stress and emotional trauma may play a role in the development of obsessive-compulsive behaviors. There is a 10 -fold increase of OCD in people with Post Traumatic Stress Syndrome (Pitman 1993) and some evidence indicating that stereotyped behaviors are precipitated by stress and naloxone reversible (Carrion 1995; Noel and Gratton 1995) lends some support to this contention. It is possible that due to a heightened sensitivity to stress, some FHP males are predisposed to explore a number of neurobehavioral adaptive strategies, including context-specific obsessive-compulsive symptomology as well as ethanol use.

There is at least one additional caveat to these findings. Earlier studies suggest that the Obsessive-Compulsive subscale of the SCL-90-R may also be measuring cognitive deficits (Derogatis et al. 1976; O'Donnell et al. 1984). If this is true, FHP males may be predisposed toward initial ethanol use to modulate the effects of premorbid cognitive impairment. This idea is supported by findings suggesting FHP males demonstrate cognitive deficits similar to that found in mild prefrontal/ frontal cortical trauma (Pihl et al. 1989), including: impaired performance on attention sensitive tasks using evoked potential paradigms (O'Connor et al. 1986; Steinhauer et al. 1987; Steinhauer and Hill 1993; Begleiter et al. 1984); memory, abstraction and problem-solving tasks (Harden and Pihl 1988). Interestingly, obsessional thinking and the stereotyped compulsive behaviors seen with frontal lobe impairments are also conceptually similar to craving and compulsive ethanol seeking.

Taken together, the findings presented here suggest that FHP males have altered hypothalamic opioid activity associated with specific psychological symptomology. The increased obsessive-compulsive symptomology observed in non-alcohol dependent FHP males indicates the existence of this symptomology prior to the onset of the effects of heavy ethanol use. It is possible that "craving" (Modell et al. 1992a) and obsessive symptomology reported by abstinent alcoholics (Mer- 
cier et al. 1992) in previous studies and the obsessive symptomology reported by FHP males in our sample share a common underlying neural substrate.

\section{ACKNOWLEDGMENT}

This work was supported by NIH grant RO1-AA10158 (GSW), The Alcohol Medical Research Foundation (GSW), a generous gift from The Kenneth Lattman Foundation (GSW).

\section{REFERENCES}

Alterman AI, Petrarulo EW, Tarter RE, McGowan JR (1983): Hyperactivity and alcoholism: Familial and behavioral correlates. Addictive Behavior 7:413-421

Altman DG (1991): Practical Statistics for Medical Research, $1^{\text {st }}$ ed. New York, Chapman and Hall

American Psychiatric Association (1994): Diagnostic and Statistical Manual of Mental Disorders, $4^{\text {th }}$ ed. Washington, American Psychiatric Press

Anton RF (1996): Neurobehavioral basis for the pharmacotherapy of alcoholism: Current and future directions. Alcohol and Alcoholism 31:43-53

Anton RF, Moak DH, Latham P (1995): The obsessive-compulsive drinking scale: A self-rated instrument for the quantification of thoughts about alcohol and drinking behavior. Alcoholism: Clin Exp Res 19:92-99

Baker DE, Stephenson LA (1995): Personality characteristics of adult children of alcoholics. J Clin Psycho 51:694-702

Baxter LR, Schwartz JM, Bergman KS (1992): Caudate glucose metabolic rate changes with both drug and behavior therapy for obsessive-compulsive disorder. Arch Gen Psychiatry 49:681-689

Baxter LR, Schwartz JM, Guze BH (1991): Brain imaging: Toward a neuroanatomy of ocd. In Zohar Y, Insel TR, Rasmussen S (eds), The psychobiology of obsessive compulsive disorder. New York, Springer-Verlag, pp 101-125

Begleiter H, Porhesz B, Bihari B, Kissin B (1984): Eventrelated brain potentials in boys at risk for alcoholism. Science 225:1493-1496

Blevins LS, Dobs AS, Wand GS (1994): Naloxone-induced activation of the hypothalamic-pituitary-adrenal axis in suspected central adrenal insufficiency. Am J Med Sci 308:167-170

Buccholz KK, Cadoret R, Cloninger CR, Dinwiddie SH, Hesselbrock VM, Nurnberger Jr JI, Reich T, Schmidt I, Schuckit MA (1994): A new, semi-structured psychiatric interview for use in genetic linkage studies: A report of the reliability of the SSAGA. J Stud. Alcohol 55:149-158

Bush SI, Ballard ME, Fremouw W (1995): Attributional Style, depressive features, and self-esteem: Adult children of alcoholic and nonalcoholic parents. J Youth and Adolescence 24(2):177-185

Carrion VG (1995): Naltrexone for the treatment of trichotillomania: A case report. J Clin Psychopharmacol 15 (6):444-445
Catafau AM, Etcheberrigaray A, Perez de los Cobos J, Estorch M, Guardia J, Flotats A, Berna L, Marf C, Casas M, Carrio I (1998): Regional cerebral blood flow changes in chronic alcoholic patients induced by naltrexone challenge during detoxification. J of Nuclear Medicine 40:19-24.

Cloninger CR (1981): Inheritance of Alcohol Abuse: Crossfostering analysis of adopted men. Arch Gen Psychiatry 38:861-868

Cohen MR, Cohen RM, Pickar D, Weingartner H, Murphy DL (1983): High-dose naloxone infusions in normals: Dose-dependent behavioral, hormonal and physiological responses. Arch Gen Psychiatry 40:613-619

Deckel AW, Hesselbrock V, Bauer L (1995): Relationship between alcohol-related expectancies and anterior brain functioning in young men at risk for developing alcoholism. Alcoholism: Clin Exp Res 19:476-481

Derogatis LR (1977): SCL-90-R Administration, Scoring and Procedures Manual. Minneapolis, MN: National Computer Systems

Derogatis LR, Cleary PA (1977a): Factorial invariance across gender for the primary symptom dimensions of the SCL-90-R. Br J Soc Clin Psychol 16:347-356

Derogatis LR, Cleary PA (1977b): Confirmation of the dimensional structure of the SCL-90-R A study in construct validation. J Clin Psychol 33:981-989

Derogatis LR, Rickels K, Rock AF (1976): The SCL-90-R and the MMPI - A step in the validation of a new self-report scale. Br J Psychiatry 128:280-289

DeSoto CB, O’Donnell WE, Allred LJ, Lopes CE (1985): Symptomology in alcoholics at various stages of abstinence. Alcoholism: Clin Exp Res 9(6): 505-512

Dodman NH, Shuster L, Court MH, Patel J (1988): Use of a narcotic antagonist (nalmefene) to suppress self-mutilative behavior in a stallion. JAVMA 192:1585-1586

Franzblau SH, Kanadanian M, Rettig E (1995): Critique of reductionistic models of obsessive-compulsive disorder: Toward a new explanatory paradigm. Soc Sci Med 41(1):99-112

Froelich JC, Wand GS (1997): The neurobiology of ethanolopioid interactions in ethanol reinforcement. Alcoholism: Clin Exp Res 20: 181A-186A

Gianoulakis C, Krishnan B, Thavundayil J (1996): Enhanced sensitivity of pituitary $\beta$-endorphin to ethanol in subjects at high risk of alcoholism. Arch Gen Psychiatry 53:250-257

Gietzen DW (1990): Animal models elucidate the role of serotonin in OCD. Psychiat Times 7:17-18

Gillen R, Hesselbrock V (1992): Cognitive functioning, ASP, and family history of alcoholism in young men at risk for alcoholism. Alcoholism: Clin Exp Res 16:206-214

Goldstein A (1976): Opioid peptides (endorphins) in pituitary and brain. Science 93:1081-1086

Goodman WK, Price LH, Rasmussen SA (1989): Efficacy of fluvoxamine in obsessive-compulsive disorder: A double-blind comparison with placebo. Arch Gen Psychiatry $46: 36-43$ 
Goodwin DW, Schulsinger F, Hermansen L, Guze B and Winokur G (1973): Alcohol problems in adoptees raised apart from alcoholic biological parents. Arch Gen Psychiatry 28:238-243

Goodwin DW, Schulsinger F, Knop J, Mednick S and Guze SB (1974): Alcoholism and depression in the adopted-out daughters of alcoholics. Arch Gen Psychiatry 34:751-755

Goodwin DW (1985): Alcoholism and genetics. Arch Gen Psychiatry 42:171-174

Hammer RP Jr, Zhou L, Cheung S (1994): Gonadal steroid hormones and hypothalamic opioid circuitry. Horm Behav 28(4):431-437

Harden P, Pihl RO (1988): Cognitive and behavioral characteristics of adolescent sons of alcoholics. Paper presented at the annual meeting of the Canadian Psychological Association, Montreal and Quebec, Canada.

Hartka E, Johnstone B, Leino V, Motoyoshi M, Temple MT, Fillmore MP (1991): A meta-analysis of depressive symptomatology and alcohol consumption over time. Br J Addict 85:1283-1296

Helzer JE, Pryzbeck, TR (1988): The co-occurrence of alcoholism with other psychiatric disorders in the general population and its impact on treatment. J Stud Alcohol 49:219-224

Helzer JE, Burnam A, McEvoy L (1988). Alcohol abuse and dependence. In Robins LN, and Reiger DA (eds), Psychiatric Disorders in America: The Epidemiological Catchment area study. New York, Free Press, pp. 81-115

Herz A (1997): Endogenous opioid systems and alcohol addiction. Psychopharmacology 129:99-111

Insel TR (1988): Obsessive compulsive disorder: A neuroethological perspective. Psychopharmacol Bul 24:365-369

Insel TR (1990): Phenomenology of obsessive-compulsive disorder. J Clin Psychiat 51(2): 4-8

Insel TR, Pickar D (1983): Naloxone administration in obsessive-compulsive disorder: Report of two cases. Am J Psychiatry 140:1219-1220

Joshi D, Lekhtman I, Billiar RB, Miller MM (1993); Gonadotropin hormone-releasing hormone induced luteinizing hormone responses in young and old female C57BL/6J mice. Proc Soc Exp Biol Med 204(2):191-194

Keuler DJ, Altemus M, Michelson D, Greenberg B, Murphy DL (1996): Behavioral effects of naloxone infusion in obsessive-compulsive disorder. Biol Psychiatry 40:154-156

Kosten T, Anton S, Rounsaville B (1992): Ascertaining psychiatric diagnoses with the family history method in a substance abuse population. J. Psychiat Res 26:135-147

Kranzler HR, Anton RF (1994): Implications of recent neuropsychopharmacologic research for understanding etiology and development of alcoholism. J Consult Clin Psychol 62:1116-1126

Kushner MG, Sher KJ (1992): Anxiety and drinking behavior: Moderating effects of alcohol-related expectancies. Paper presented at the annual meeting for the Association for the Advancement of Behavior Therapy, Washington, DC.

Lex BW, Ellingboe JE, Teoh SK, Mendelson JH, Rhoades E (1991): Prolactin and cortisol levels following acute alcohol challenge in women with and without a family history of alcoholism. Alcohol 8:383-387
Martin ED, Sher KJ (1994): Family history of alcoholism, alcohol use disorders and the five-factor model of personality. J Stud Alcohol 55: 81-90

Martin del Campo AF, Dowson JH, Herbert J, Paykel ES (1994): Effects of naloxone on diurnal rhythms in mood and endocrine function: A dose-response study in man. Psychopharmacology 114:583-590

Martin del Campo AF, McMurray F, Besser GM, and Grossman A (1992): Effect of 12-hour infusion of naloxone on mood and cognition in normal male volunteers. Biol Psychiatry 32:344-353

McGue M, Pickens RW, Svikis DS (1992): Sex and age effects on the inheritance of alcohol problems: A twin study. J Abn Psychol 101:3-17

Mercier C, Brochu S, Girard M, Gravel J, Quellet R, Pare R (1992): Profiles of alcoholics according to the SCL-90-R: A confirmative study. International J Addict 27(11): $1267-1282$

Moak DH, Anton RF, Latham PK (1998): Further validation of the Obsessive-Compulsive Drinking Scale (OCDS). Am J Addict 7:14-23

Modell JG, Glaser FB, Mountz JM (1992a): Obsessive and compulsive characteristics of craving for alcohol in alcohol abuse and dependence. Alcoholism: Clin Exp Res $16: 272-274$

Modell JG, Glaser FB, Mountz JM, Schmaltz S, Cyr L (1992b): Obsessive and compulsive characteristics of alcohol abuse and dependence: Quantification by a newly developed questionnaire. Alcoholism: Clin Exp Res $16: 266-271$

Naber D (1993): Opioids in the etiology and treatment of psychiatric disorders. In Herz A (ed), Opioids II. New York, Springer, pp 81-801

Naranjo CA, Seller EM, Sullivan JT, Woodley DV, Kadlek K, Sykor K (1987): The serotonin uptake inhibitor citalopram attenuates ethanol intake. Clin Pharmacol Ther 41:266-274

Newlin DB, Thomson JB (1990): Alcohol challenge with sons of alcoholics: A critical review and analysis. Psychol Bull 108:383-402

Noel MB, Gratton A (1995): Electrochemical evidence of increased dopamine transmission in prefrontal cortex and nucleus accumbens elicited by ventral tegmental $\mu$-opioid receptor activation in freely behaving rats. Synapse 21:110-122

Nurnberg HG, Keith S, Paxton DM (1997): Consideration of the relevance of ethological animal models for human repetitive behavioral spectrum disorders. Biol Psychiatry 41:226-229

Nylander I, Rydelius PA (1982): A comparison between children of alcoholic fathers from excellent versus poor social conditions. Acta Pediatrica Scandinavia 71:809-813

O'Connor S, Hesselbrock V, Tasman A (1986): Correlates of increased risk for alcoholism in young men. Progress in Neuropsychopharmacology and Biological Psychiatry 10:211-218

O'Donnell WE, DeSoto CB, Reynolds DM (1984): A cognitive deficit subscale of the SCL-90-R. J Clin Psychol 40 (1):241-246 
Olson, GA, Olson RD, Kastin AJ (1996): Endogenous opiates. Peptides 17(8):1421-1466

Pickar D, Cohen MR, Naber D, Cohen RM (1982): Clinical studies of the endogenous opioid system. Biopsychiatry 17 (11):1243-1276

Pihl RO, Peterson J, Finn P (1990): Inherited predisposition to alcoholism: Characteristics of sons of male alcoholics. J Abn Psychol 99:291-301

Pihl RO, Finn P, Peterson JB (1989): Autonomic hyperactivity and risk for alcoholism. Progress in Neuropsychopharmacology and Biological Psychiatry 13:489-496

Pitman RK (1993): Posttraumatic obsessive-compulsive disorder: a case study. Comprehens Psychiat 34:102-107

Pohorecky LA (1991): Stress and alcohol interaction: An update of Human research. Alcoholism: Clin Exp Res 15 (3):438-459

Priest CA, Eckersell CB, Micevych PE (1995): Estrogen regulates proenkephalin mRNA levels in the rat ventral medial nucleus: Temporal and cellular aspects. Molecular Brain Res 28:251-262

Rapoport JL (1990): Obsessive compulsive disorder and basal ganglia dysfunction. Psychol Med 20:465-469.

Rapoport JL, Ryland DH, Kriete M (1992): Drug treatment of canine acral lick: An animal model of obsessive-compulsive disorder. Arch Gen Psychiatry 49:517-521

Rasmussen SA, Tsuang MT (1984): The epidemiology of obsessive-compulsive disorder. J Clin Psychiat 45:450-457

Reid LD, Delconte JD, Nichols ML, Bilsky EJ, Hubbell CL (1991): Test of opioid deficiency hypothesis of alcoholism. Alcohol 8:247-257

Romano GJ, Mobb CV, Howell RD, Pfaff DW (1989): Estrogen regulation of proenkephalin gene expression in the hypothalamus of the rat: Temporal qualities and synergism with progesterone. Molecular Brain Res 5:51-58

Sandyk R (1987): Naloxone abolishes obsessive-compulsive behavior in Tourette's syndrome. Int J Neurosci 35:93-94

Saunders GR, Schuckit MA (1981): MMPI scores in young men with alcoholic relatives and controls. J Nerv Ment Dis 160:456-458

Schuckit MA, Risch SC, Gold EO (1988): Alcohol consumption, ACTH level, and family history of alcoholism. Am J Psychiatry 145:1391-1395

Schuckit MA, Tsuang JW, Anthenelli RM, Tipp JE, Nurnberger JI (1996): Alcohol challenges in young men from alcoholic pedigrees and control families: A report from the COGA project. J Stud Alcohol 57:368-377

Schuckit MA (1981): Peak blood alcohol levels in men at high risk for the future development of alcoholism. Alcoholism: Clin Exp Res 5:64-66

Schulsinger F, Knop J, Goodwin DW, Teasdale TW, Mikkelson U (1985): A prospective study of young men at high risk for alcoholism: Social and psychological characteristics. Arch Gen Psychiatry 93:755-60

Sher KJ, Levenson RW (1982): Risk for alcoholism and indi- vidual differences in the stress response dampening effect of alcohol. J Abn Psychol 91:350-367

Sher KJ, Walitzer KS, Wood PK, Brent EE (1991): Characteristics of children of alcoholics: Putative risk factors, substance use and abuse, and psychopathology. J Abn Psychol 100:427-448

SPSS Inc. (1996): SPSS Base 7.0 for Windows User's Guide. Chicago, SPSS Inc.

Stein DJ, Dodman NH, Borchelt P, Hollander E (1994): Behavioral disorders in veterinary practice: Relevance to psychiatry. Compr Psychiatry 35:275-285

Steinhauer SR, Hill SY (1993): Auditory event-related potentials in children at high risk for alcoholism. J Stud Alcohol 54:408-421

Steinhauer SR, Hill SY, Zubin J (1987): Event-related potentials in alcoholics and their first-degree relatives. Alcohol 4:307-314

Steketee G, Grayson J, Foa EB (1987): A comparison of characteristics of obsessive-compulsive disorder and other anxiety disorders. J Anxiety Disorders 1:325-332

Ulm RR, Volpicelli JR, Volpicelli LA (1995): Opiates and alcohol self-administration in animals. J Clin Psychiatry 56:5-14

Waltman C, McCaul ME, Wand GS (1994): Adrenocorticotropin responses following administration of ethanol and ovine corticotropin-releasing hormone in the sons of alcoholics and control subjects. Alcohol Clin Exp Res $18: 826-830$

Wand GS, Dobs, AS (1991): Alterations in the hypothalamicpituitary-adrenal axis in actively drinking alcoholics. J Clin Endocrinol and Metab 72:1290-1295

Wand GS, Mangold DL, El Deiry S, McCaul ME, Hoover D. (1998): Family History of Alcoholism and Hypothalamic Opioidergic Activity. Arch Gen Psychiatry 55(12):1114-1120.

Wand GS, Mangold D, Ali M (1999): Adrenocorticotropin responses to naloxone in sons of alcohol-dependent men. J Clin Endocrin and Metab 84(1):64-68

Wand, GS (1999): HPA Changes and Risk for Alcoholism. NIAAA Research Monograph. In press.

Weizman R, Gil-Ad I, Hermesh H, Munitz H, Laron Z (1990): Immunoreactive $\beta$-endorphin, cortisol and growth hormone plasma levels in obsessive-compulsive disorder. Clin Neuropharmacol 13:297-332

Whipple SC, Noble EP (1991): Personality characteristics of alcoholic fathers and their sons. J. Stud Alcohol 52:331-337

Windle M (1990): Temperament and personality attributes of children of alcoholics. In Windle M, Searles JS (eds), Children of Alcoholics: Critical Perspectives. New York, Guilford Press, pp 129-167

Zubieta JK, Gorelick DA, Stauffer R, Ravert H, Dannals R, Frost JJ (1996): Increased mu opioid receptor binding detected by pet in cocaine dependent men is associated with cocaine craving. Nature Medicine 2 (11): 1225-1229 